\title{
Benign Salivary Gland Tumour Presenting as Unilateral Nasal Mass: Case Report of Pleomorphic Adenoma of Nasal Septum
}

\section{Gvs Rao ${ }^{1}$, Laxminath Ganji ${ }^{1}$, Chaitanya Rao ${ }^{1}$, Shree Rao', Prudviraju Moganti' ${ }^{1}$, Monalisa Hui ${ }^{2}$, Shantveer G. Uppin ${ }^{2}$, Ch Tejaswini ${ }^{3}$}

${ }^{1}$ Dr Raos ENT Superspeciality International Hospital, Hyderabad, India

${ }^{2}$ Nizam's Institute of Medical Sciences, Hyderabad, India

${ }^{3}$ Basavatarakam Indo American Cancer Hospital \& Research Institute, Hyderabad, India

Email: ^drgvsrao@raosentcare.com

How to cite this paper: Rao, G., Ganji, L., Rao, C., Rao, S., Moganti, P., Hui, M., Uppin, S.G. and Tejaswini, C. (2021) Benign Salivary Gland Tumour Presenting as Unilateral Nasal Mass: Case Report of Pleomorphic Adenoma of Nasal Septum. International Journal of Otolaryngology and Head \& Neck Surgery, 10, 511-518.

https://doi.org/10.4236/ijohns.2021.106045

Received: October 6, 2021

Accepted: November 8, 2021

Published: November 11, 2021

Copyright $\odot 2021$ by author(s) and Scientific Research Publishing Inc. This work is licensed under the Creative Commons Attribution International License (CC BY 4.0).

http://creativecommons.org/licenses/by/4.0/

\section{(c) (i) Open Access}

\begin{abstract}
Introduction: Unilateral nasal mass can be benign or malignant. Very rarely we will find benign salivary gland tumor in nasal cavity. Pleomorphic adenoma is still the most common pathological variety either in major or minor salivary gland tumors. In the nasal cavity, even though most of the accessory salivary glands are present in the lateral wall of nose, nasal septum remains the most common site of origin. Case Report: A 40-year-old female presented with right-sided nasal obstruction and epistaxis. CT scan of Nose and Paranasal sinuses found a lesion involving the anterior third of the right nasal cavity. The patient underwent complete surgical resection of the tumor via an endonasal approach. Histological examination found a mixed cellular component (epithelial and myoepithelial) and mesenchymatous tissue with chondromyxoid stroma, enabling diagnosis of a typical pleomorphic adenoma. Conclusion: Pleomorphic adenoma is the most common salivary gland tumor but rare to find in the nasal cavity with only few cases reported in the literature. Although benign, the risk of local recurrence, malignant transformation and metastasis requires close long-term follow-up.
\end{abstract}

\section{Keywords}

Pleomorphic Adenoma (PA), Benign Salivary Gland Tumour, Nasal Mass, Nasal Septum

\section{Introduction}

Unilateral nasal mass may be due to neoplastic and non-neoplastic lesions. They 
constitute $6 \%$ of all sinonasal pathologies [1]. It is a common practice to assume that unilateral nasal mass in adults is either an inverted papilloma or a malignant lesion. In a study, the most common differential diagnoses for unilateral nasal mass were nasal polyposis (22\%), antrochoanal polyp (19\%), chronic rhinosinusitis $(13 \%)$, concha bullosa (11\%), inverted papilloma (6\%) and retention cysts (6\%). Many other causes were found less commonly and included fibrous dysplasia, mucocele, lymphoma, schwannoma, ameloblastoma, pleomorphic adenoma, myxoma and squamous cell carcinoma [2]. However, the location of the lesion does help to narrow the diagnosis, as septal lesions are less common than sinonasal lesions [3]. Here we are presenting an uncommon case of unilateral nasal mass which was diagnosed as benign salivary gland tumor.

Salivary gland tumors constitute about 3\% of all neoplasms [4]. Pleomorphic adenoma or mixed tumor of the salivary gland constitutes $60 \%$ of all salivary gland neoplasms. $65 \%$ percent of cases involve major salivary glands, mainly the parotid and 35\% involve the accessory salivary glands, mainly the oral cavity and especially the palate [5]. Although few cases have been reported in other sites, PA of the nasal cavity is still rarely observed [6]. Among all reported cases of pleomorphic adenomas in the nasal cavity, $80 \%$ arose from the mucosa of cartilaginous or bony septum and only $20 \%$ originated from the lateral nasal wall [7]. Ersner and Saltzman suggested that the ectopic embryonic epithelialized cells on the nasal septal mucosa, which appeared during the migration of the nasal buds, are precursors of the septal pleomorphic adenomas [8]. Our objective is to briefly discuss about clinical presentation, radiological findings, histological features and management of this rare case.

\section{Case Presentation}

A 40 year old woman presented with one year history of right sided nasal obstruction and bleeding from right side nose occasionally. There was partial nasal obstruction initially but from past 6 months it was complete obstruction. There is a past history of nose surgery probably bilateral partial turbinectomy done 20 years back. She never had any significant nasal complaints until last 1 year. There was no external deformity and no visual defects. Her weight was stable and her general health was satisfactory.

Rigid nasal endoscopy revealed a deviated septum to the left and a large polypoidal mass filling the right nasal cavity. Probe was passed all around except medial side, which suggests probable attachment to septum. There was no bleeding on touch. There was no evidence of rhino-sinusitis and her postnasal space was normal. There was no cervical lymphadenopathy.

Radiological examination (CT scan) demonstrated well pneumatised Para-nasal sinuses and an expansile soft tissue density lesion in the anterior aspect of the right nasal cavity. Septum is pushed towards left side causing narrowing of the contralateral nasal cavity with indentation of left inferior turbinate (Figures 1(A)-(D)). The smooth surface, preservation of mucosal lining and the localized nature of the mass were consistent with a benign lesion. 


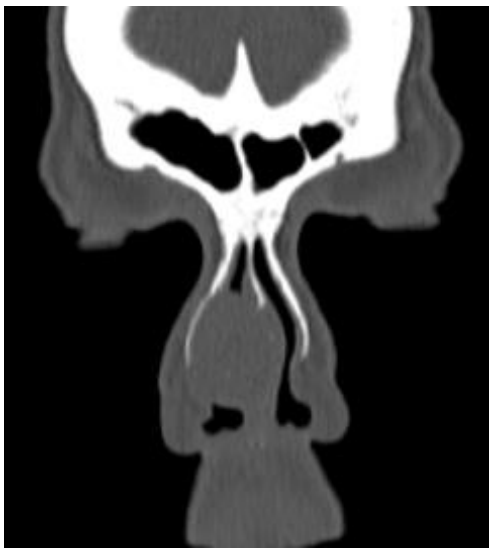

(A)

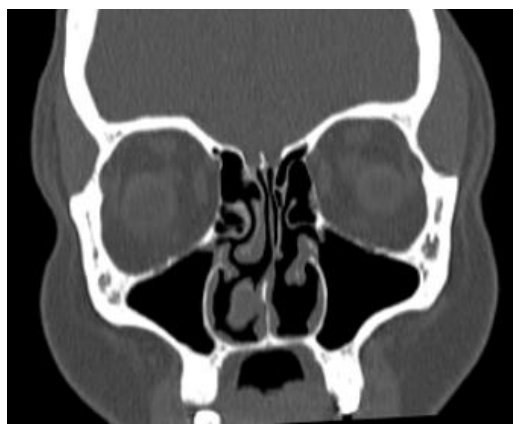

(C)

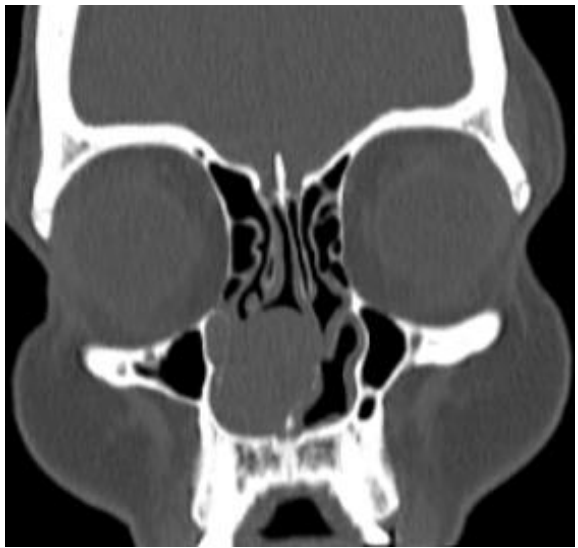

(B)

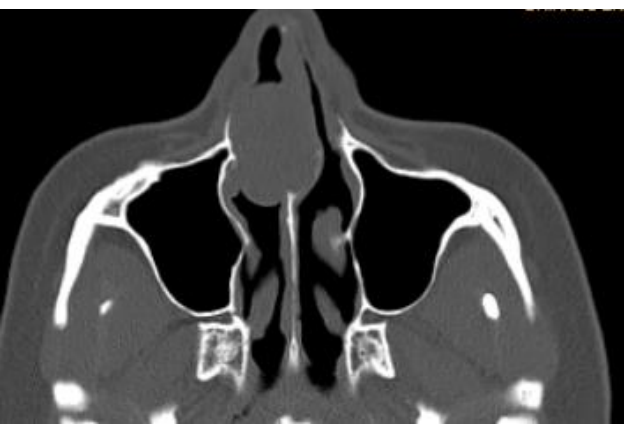

(D)

Figure 1. (A, B, C, D) CT PNS coronal sections showing a relatively well defined expansile soft tissue density lesion in the anterior portion of the right nasal fossa with deviated nasal septum to the left, and thinning of the right nasal bone can be noted. Narrowing of the contralateral nasal cavity noted with indentation of left inferior turbinate.

We conducted Excision biopsy of the mass as it appeared to be a benign tumour mostly confined to anterior nasal cavity. Intra-operatively we found smooth, lobulated and firm mass arising from the Right anterior septal mucosa (Figure $2(\mathrm{~A})$ ), occupying the entire anterior nasal cavity, pushing the septum to the opposite side and causing pressure ulceration of the lateral wall mucosa above remnant inferior turbinate. There was another small attachment noticed over the septal mucosa at the vomero-cartilaginous region (Figure 2(B)). Complete excision from anterior attachment with $5 \mathrm{~mm}$ free margin until cartilage is exposed was done. Posterior attachment was excised with the segment of vomerine bone and cartilaginous septum attached to it. The septal mucosa of the opposite side was preserved. The patient was discharged on the same day and the postoperative period was uneventful.

Histopathological analysis of the tumor has shown cellular lesion comprising of ductal epithelial cells and myoepithelial cells in a myxoid stroma (Figure $3(\mathrm{~A})$ ) suggesting a benign pleomorphic adenoma with no focus of malignant change. The resection margins were clear. Immunohistochemistry shown CK 7 positive in the ductal epithelial cells (Figure 3(B)), p63 and calponin highlights the myoepithelial cells (Figure $3(\mathrm{C})$ ) indicating benign salivary gland neoplasm 


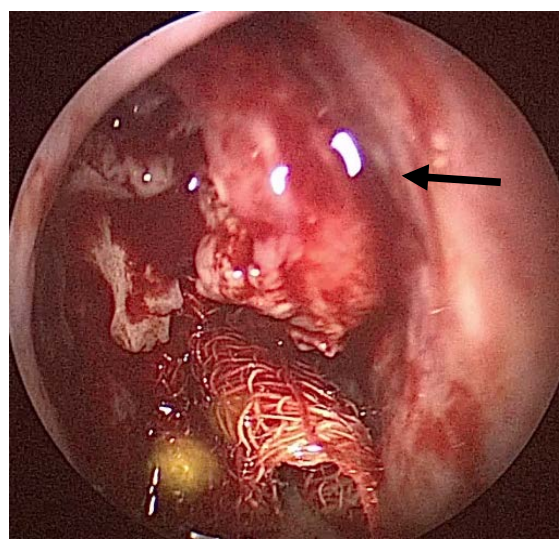

(A)

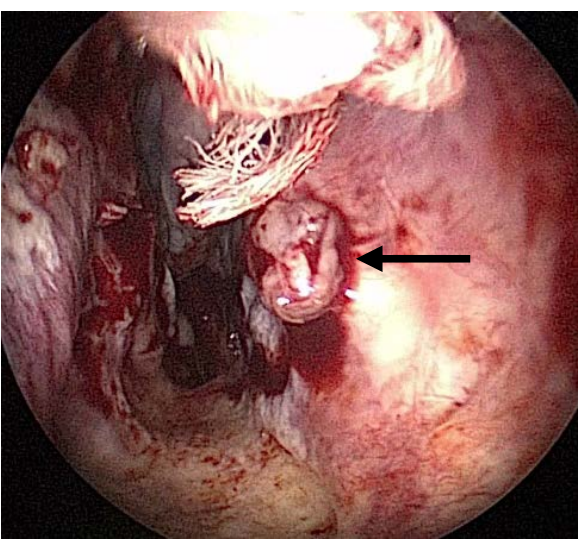

(B)

Figure 2. (A) intra operative endoscopic picture showing partially debulked tumor with its attachment to septum (black arrow), (B) picture showing tumor attachment (black arrow) to the mucosa of bony (vomer) cartilaginous junction.

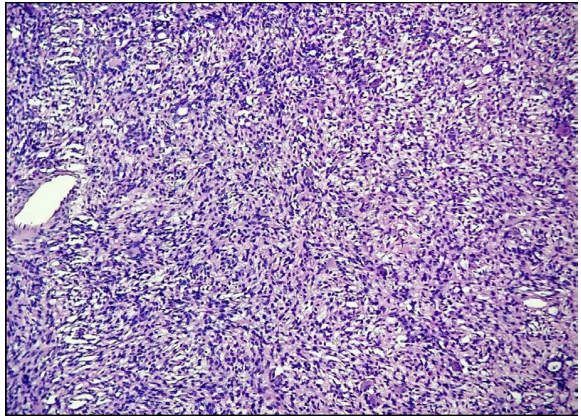

(A)

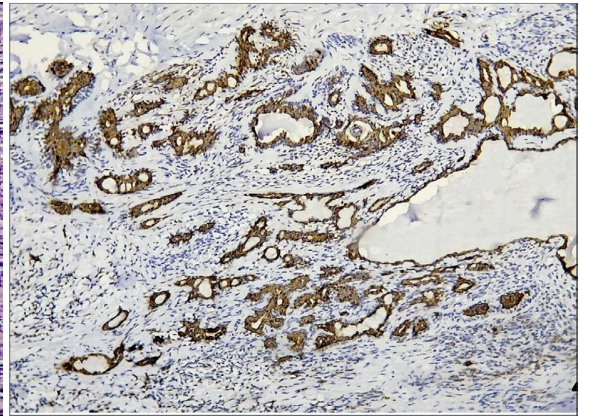

(B)

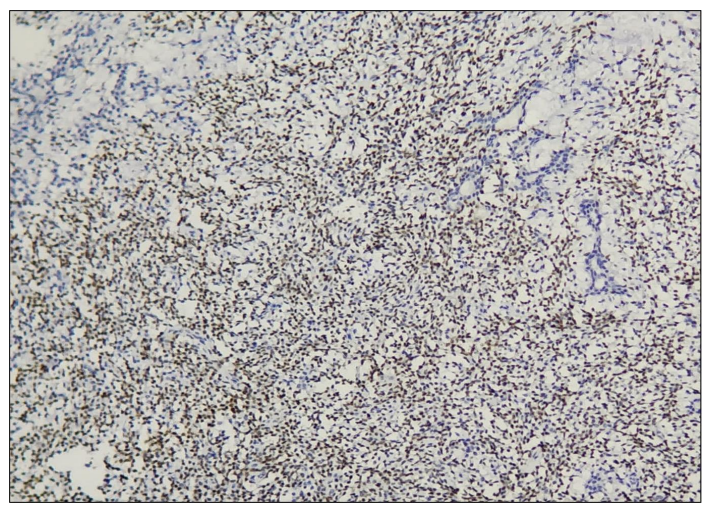

(C)

Figure 3. HPE (A) and IHC (B \& C) pictures. (A) Cellular lesion comprising of ductal epithelial cells and myoepithelial cells in a myxoid stroma (H \& E; $\times 100$ and 400); (B) CK 7 positive in the ductal epithelial cells; (C) p63 and calponin highlights the myoepithelial cells.

consistent with pleomorphic adenoma. As it was benign tumor, no further treatment was advised except regular follow ups. Patient was under regular follow up for 2 years without any nasal complaints and repeated nasal endoscopic examination revealed no recurrence of the disease. 


\section{Discussion}

Pleomorphic adenoma (PA) is a mixed, usually benign tumor of the main salivary glands, mostly observed in the parotid gland [9]. It is less frequent in minor salivary glands of the hard and soft palates. Other rare sites are the upper aerodigestive tract including the nasal cavity, pharynx, larynx, trachea, and lacrimal glands [10]. In the upper respiratory tract, the most favored site of origin is the nasal cavity, followed by the maxillary sinus and the nasopharynx [11]. Denker and Kahler [12] first reported the case of pleomorphic adenoma of the nasal cavity in 1929. The majority of intranasal PAs arise from the nasal septum. In our case the origin of the tumor was from nasal septum. PAs originating from the lateral wall and inferior turbinate account for only $9.8 \%-20 \%$ of the reported cases, although most of the minor salivary glands are located in the lateral nasal wall and turbinates [13].

According to Stevenson, remnants of the vomero-nasal organ, an epitheliumlined duct in the cartilaginous nasal septum degenerated in early fetus, could be the reason for the appearance of these tumors in this particular region [14]. According to Evans and Cruikshank, it originates directly from the matured salivary glandular tissue [15]. Larger studies of intranasal pleomorphic adenoma include 40 cases reported by Compagno and Wong and 59 cases reported by Wakami et al. [7] [16].

Intranasal PA is more frequently seen in women and occurs between the third and sixth decades of life [10]. In our case the patient is typically middle-aged woman. There is no reported correlation with occupational exposure or inhaled toxic chemical compounds. It is generally known to be a slow-growing tumor and therefore clinical symptoms appear after a long silent period.

Typical presenting features include unilateral nasal obstruction (71\%) and epistaxis (56\%). Other signs and symptoms include a mass in the nose, nasal swelling, epiphora, and mucopurulent rhinorrhea [7]. PAs are dome-shaped, exophytic, polypoid, oval, firm, gray, smooth and capsulated masses. No destruction of the surrounding tissue is observed [17]. The tumor size varies from $5 \mathrm{~mm}$ to 7 $\mathrm{cm}$ [10]. Our patient presented with unilateral nasal obstruction and epistaxis. On endoscopy there was a smooth, polypoidal and firm mass.

The most useful imaging studies for diagnosis of intranasal PA are CT and MRI. The role of these techniques is to detect the mass and to determine its origin. However, it is difficult to demonstrate the origin when the masses reach larger sizes. CT may reveal a well-defined, lobulated mass displacing the nasal septum on nonenhanced images. PAs arising from the nasal septum are usually multilobulated on CT and MRI, as noted by Motoori et al. [18]. CT is useful to demonstrate the calcifications within the tumor and adjacent bony changes. Although scattered punctate calcification has been reported on non enhanced images [18], calcification was not present in our case. In this patient on CT PNS the tumor measured $3 \times 2.5 \times 2.5 \mathrm{~cm}$.

Histologic appearance of pleomorphic adenoma includes admixture of epi- 
thelial, myoepithelial and stromal components, including the presence of acini or tubules and a myxochondroid stroma. Pleomorphic adenomas of the aero digestive tract are characterized by epithelial tissue mixed with mucoid or chondroid tissue appearance. They have high cellularity and lack of a stromal component, because of which they resemble aggressive epithelial tumors [7]. Nasal pleomorphic adenoma thus is frequently interpreted as more aggressive neoplasm based on initial biopsy results. Many cases of misdiagnosis of pleomorphic adenoma of the nasal cavity such as squamous cell carcinoma, adenoid cystic carcinoma and adenocarcinoma are reported in the literature [19].

Immunohistochemical analysis (IHC) plays an important role in determining the accurate diagnosis. In a classical PA, the IHC stains positive for various cytokeratins, S100 protein, glial fibrillary acid protein (GFAP) and Vimentin, a smooth muscle actine (SMA). This describes the "mixed" nature of the tumor, namely, the stromal and the epithelial line [20]. On contrary to the mixed nature of PA, in our case the lesion is cellular and the ductal epithelial cells are highlighted on Ck7 and the myoepithelial cells are highlighted on p63 and calponin. Ki67 labelling index is low staining $2 \%$ of the cell representing the benign nature of the tumor.

The treatment of choice for pleomorphic adenoma in the nasal cavity is local surgical excision with histologically clear margins [21]. In the case of intranasal pleomorphic adenoma, several surgical approaches have been used to achieve wide local clearance and these include intranasal, transnasal endoscopic, external rhinoplasty, lateral rhinotomy and mid facial degloving [22]. We did transnasal endoscopic excision of the tumor with clear margins. For nasal PA, Compagno and Wong reported three cases of local recurrence among 40 patients $(7.5 \%)$ at 3 years' follow-up [7]. The risk of malignant transformation is 6\% [5] and is estimated at $1.5 \%$ within 5 years in the absence of resection [23]. Röijer et al. suggested that amplification and over expression of HMGIC and possibly MDM2 may be genetic factors for malignant transformation of PA [24].

There has also been a report of metastasis to the submandibular lymph-node, in a recurrent septal pleomorphic adenoma, 17 years after the first diagnosis. Even in this case, the microscopic features of both the primary and metastatic lesion were benign. In this regard, an iatrogenic theory has been proposed. This theory suggests that the metastasis occurs because of incomplete excision or inadvertent disruption of the tumor with consequent spread through hematogenous or lymphatic routes. Pulmonary, hepatic and bone metastasis have also been reported [25]. Nevertheless, postoperative follow-up is necessary for all patients with intranasal PA because as many as $10 \%$ of patients may experience a recurrence despite wide local excision with clear margins [17].

\section{Conclusion}

Pleomorphic adenoma presenting as a slow-growing unilateral nasal mass is very rare, it is important to consider among various differential diagnoses. Rigid nasal 
endoscopy and CT scan will help to know physical characteristics and extent of the tumor, guiding us to differentiate between benign and malignant lesions in cases presenting early. Complete Excision biopsy by transnasal endoscopic approach is almost always preferred whenever suspecting benign lesion. In early presentation when confined to nasal cavity, excision biopsy serves as both diagnostic and therapeutic procedure. As pleomorphic adenoma has chances of recurrence and malignant transformation, always all the patients are advised longterm follow-up with both endoscopic and radiological investigations whenever necessary.

\section{Conflicts of Interest}

The authors declare no conflicts of interest regarding the publication of this paper.

\section{References}

[1] Rudralingam, M., Jones, K. and Woolford, T.J. (2002) The Unilateral Opaque Maxillary Sinus on Computed Tomography. British Journal of Oral and Maxillofacial Surgery, 40, 504-507. https://doi.org/10.1016/S0266-4356(02)00225-5

[2] Habesoglu, T.E., Habesoglu, M., Surmeli, M., Uresin, T. and Egeli, E. (2010) Unilateral Sinonasal Symptoms. Journal of Craniofacial Surgery, 21, 2019-2022. https://doi.org/10.1097/SCS.0b013e3181f5389a

[3] Valencia, M.P. and Castillo, M. (2008) Congenital and Acquired Lesions of the Nasal Septum: A Practical Guide for Differential Diagnosis. RadioGraphics, 28, 205 223. https://doi.org/10.1148/rg.281075049

[4] Jassar, P., Stafford, N. and Macdonald, A. (1999) Pleomorphic adenoma of the Nasal Septum. The Journal of Laryngology \& Otology, 113, 483-485. https://doi.org/10.1017/S0022215100144299

[5] Sciandra, D., Dispenza, F., Porcasi, R., et al. (2008) Pleomorphic adenoma of the Lateral Nasal Wall: Case Report. ACTA Otorhinolaryngologica Italica, 28, 150-153.

[6] Malinvaud, D., Couloigner, V., Badoual, C., Halimi, P., et al. (2006) Pleomorphic adenoma of the Nasal Septum and Its Relationship with Epstein-Barr Virus. Auris Nasus Larynx, 33, 417-421. https://doi.org/10.1016/j.anl.2006.05.006

[7] Compango, J. and Wong, R.T. (1977) Intranasal Mixed Turnouts (Pleomorphic adenoma): A Clinicopathologic Study of 40 Cases. American Journal of Clinical Pathology, 68, 213-218. https://doi.org/10.1093/ajcp/68.2.213

[8] Ersner, M.S. and Saltzman, M. (1944) A Mixed Tumor of the Nasal Septum. Report of a Case. The Laryngoscope, 54, 287-296. https://doi.org/10.1288/00005537-194406000-00004

[9] Yazibene, Y., Ait-Mesbah, N., Kalafate, S., Yahi-Ait Mesbah, N., Abdennebi, A., Bouzid, H., et al. (2011) Degenerative Pleomorphic adenoma of the Nasal Cavity. European Annals of Otorhinolaryngology, Head and Neck Diseases, 128, 37-40. https://doi.org/10.1016/j.anorl.2010.09.006

[10] Oztürk, E., Sağlam, O., Sönmez, G., Cüce, F. and Haholu, A. (2008) CT and MRI of an Unusual Intranasal Mass: Pleomorphic adenoma. Diagnostic and Interventional Radiology, 14, 186-188.

[11] Batsakis, J.G. (1984) Tumors of the Head and Neck. 2nd Edition, Williams and Wil- 
kin, Baltimore, 76-99.

[12] Kahler, D. (1929) Handush der Hals. Nasen Ohrenheilkunde, 5, 202.

[13] Kandoğan, T., Dalğıç, A., Gültekin, G., Ulusoy, S. and Selek, E. (2015) Pleomorphic adenoma of the Nasal Cavity. Journal of Academic Research in Medicine, 5, 25-27. https://doi.org/10.5152/jarem.2015.523

[14] Stevenson, H.N. (1932) Mixed Tumor of the Septum. Annals of Otology, Rhinology \& Laryngology, 41, 563-570. https://doi.org/10.1177/000348943204100222

[15] Evans, R.W. and Cruikshank, A.H. (1970) Epithelial Tumors of the Salivary Glands. In: Major Problems in Pathology (Vol. 1), WB Saunders, Philadelphia, 281-295.

[16] Wakami, S., Muraoka, M. and Nakai, Y. (1996) Two Cases of Pleomorphic adenoma of the Nasal Cavity. Nippon Jibiinkoka Gakkai Kaiho, 99, 38-45.

[17] Acevedo, J.L., Nolan, J., Markwell, J.K. and Thompson, D. (2010) Pleomorphic adenoma of the Nasal Cavity: A Case Report. Ear, Nose \& Throat Journal, 89, 224-226. https://doi.org/10.1177/014556131008900508

[18] Motoori, K., Takano, H., Nakano, K., Yamamoto, S., Ueda, T. and Ikeda, M. (2000) Pleomorphic adenoma of the Nasal Septum: MR Features. American Journal of Neuroradiology, 21, 1948-1950.

[19] Haberman, R.S. and Stanley, D.E. (1989) Pleomorphic adenoma of the Nasal Septum. Otolaryngologic-Head and Neck Surgery, 100, 610-612. https://doi.org/10.1177/019459988910000616

[20] Hirai, S., Matsumoto, T. and Suda, K. (2002) Pleomorphic adenoma in Nasal Cavity: Immunohistochemical Study of Three Cases. Auris Nasus Larynx, 29, 291-295. https://doi.org/10.1016/S0385-8146(01)00150-X

[21] Suzuki, K. Moribe, K. and Baba, S. (1990) A Rare Case of Pleomorphic adenoma of the Lateral Wall of the Nasal Cavity with Special Reference of Statistical Observation of Pleomorphic adenoma of the Nasal Cavity in Japan. The Oto-Rhino-Laryngological Society of Japan, 93, 740-745.

[22] Avishay, G., Yudith, B. and Milo, F. (1997) Pleomorphic Nasoseptal Adenoma. Journal of Otolaryngology, 26, 399-401.

[23] Sengul, I. and Sengul, D. (2011) Pleomorphic adenoma of the Lower Lip: A Review. North American Journal of Medicine and Science, 3, 536-539.

[24] Röijer, E., Nordkvist, A., Ström, A.K., et al. (2002) Translocation, Deletion/Amplification, and Expression of $H M G I C$ and $M D M 2$ in a Carcinoma ex Pleomorphic adenoma. The American Journal of Pathology, 160, 433-440. https://doi.org/10.1016/S0002-9440(10)64862-6

[25] Wermuth, M.J., Mann, C.H. and Odere, F. (1988) Metastasizing Pleomorphic adenoma Arising in the Soft Palate. Otolaryngologic-Head and Neck Surgery, 99, 505508. https://doi.org/10.1177/019459988809900509 